que da una antigüedad de $370+60$ a. JC. (7), por lo que podemos asegurar su pertenencia al menos a la primera mitad de este siglo IV a. C., con las consiguientes consecuencias sobre la perduración de este tipo de materiales áticos, que en este caso parecen estar vinculados a las pertenencias del propio difunto, primero en vida y luego en la muerte.

\title{
ESTUDIO DE LAS CREMACIONES DE LA SEPULTURA 11/145 DE LOS CASTELLONES DE CEAL
}

POR

\author{
JOSE M. REVERTE COMA (*)
}

\begin{abstract}
RESUMEN Se estudian los restos quemados de un varón adulto correspondiente a una tumba ibérica. Distribuidos fuera de la urna se encontraron restos faunísticos y humanos también quemados.

ABSTRACT This paper studies the cremated bones of an adult male included in an urn of Iberian date. Outside it there were some more remains, also cremated, corresponding to animals and humans.
\end{abstract}

Palabras clave Cremación. Estudio antropológico. Cultura Ibérica. Edad del Hierro.

Key words Anthropological study. Iberian Culture. Iron Age.

\section{Huesos incluidos en la urna 11/145/13}

PESO TOTAL: $1.155 \mathrm{gr}$.

Neurocráneo: 128.

Esplanocráneo: 15.

Huesos largos: 322

Vértebras: 140 .

Costillas: 68

\section{Coxales: 122.}

Manos, dedos: 16.

Omoplatos: 36.

Rótulas: 0 .

Huesos menudos: 308

COLOR: terroso, blanco sucio con tonos grises.

NEUROCRANEO: 16 fragmentos de bóveda craneal (FTPO) con dientes. El mayor mide $60 \times 48$

(7) El análisis ha sido realizado por el Dr. F. Alonso Matias, del Instituto Rocasolano (CSIC). La referencia de la muestra es: CSIC-859. La edad del Carbono 14; $2320+60$ años, con un periodo utilizado para el Carbono-14 de 5.568 años, y 1950 como año cero, lo que da como resultado la fecha indicada.

(*) Laboratorio de Antropología Forense. Universidad Complutense. Madrid. 
$\mathrm{mm}$; espesor: $10 \mathrm{~mm}$. Se puede apreciar por estos fragmentos que tenía un cráneo de fuerte espesor. Los dientes suturales están sinostosados por su cara endocraneal. En la zona diploica se ven fundidos y rotos por la explosión del cráneo por la acción del calor. Es un casco propio de varón de 40-50 años.

- 42 fragmentos de bóveda sin dientes (FTPO). El mayor mide $92 \mathrm{~mm}$.; espesor: 6-10 mm. El tamaño de los fragmentos es inhabitual en las cremaciones estudiadas hasta ahora. La P.O.I. muestra $13 \mathrm{~mm}$. de espesor a su nivel (occipital).

- Pómulo derecho. Borde orbitario grueso. Pómulo grande $(48 \times 3)$.

- Apófisis mastoides izquierda grande, rugosa, de varón con porción petrosa de temporal adherida.

- Fragmento de base de cráneo con agujero vascular.

ESPLANOCRANEO: Hemimandíbula derecha con efecto de cuarteamiento por el calor. Conserva raíz de $1^{\circ}$ molar in situ. Rama: $25 \times 79 \mathrm{~mm}$. INDICE DE RAMA: 45,7 (raza blanca mediterránea). Es excepcional quen en las cremaciones se pueda determinar el indice de rama.

- Fragmento de mandíbula (parte media) con gran apófisis propia de varón con gran musculatura masaticatoria.

- Maxilar superior derecho con alvéolos abiertos por pérdida de dientes post-morten. In situ quedan las raices de los tres molares. Conservaba toda la dentadura en el momento de la muerte.

HUESOS LARGOS: 81 fragmentos de diáfisis y epífisis de HRCFTP. El mayor mide $110 \mathrm{~mm}$. (son todos fragmentos grandes). Recia cortical.

VERTEBRAS: 59 fragmentos de cuerpos vertebrales. Axis roto.

COSTILLAS: 34 fragmentos de costillas fuertes de varón adulto.

COXALES: 62 fragmentos de ilion cortical y medular o alveolar.

OMOPLATOS: fragmentos de láminas, cavidad glenoide y acromion.

DEDOS: fragmentos de falanges medias $1^{\circ}$ y $2^{\circ}$ de la mano.

PIE: fragmento de astrágalo de varón adulto.

CONCLUSIONES: Restos óseos cremados que parecen pertenecer a un solo sujeto varón de 3050 años, recio, de fuerte osamenta e inserciones de fuertes músculos masticatorios, buen comedor de carne y otras sustancias duras. Conservaba toda la dentadura. No hay huellas de artrosis. Tenía un cráneo grande, de fuerte espesor cortical.

\section{Huesos quemados situados fuera de la urna cineraria}

11/145/6. Fragmento de costilla juvenil de aspecto femenino.

Fragmento de hueso largo (diáfisis) de poco espesor cortical.

Fragmento de coxal (ilion) correspondiente a carita auricular cóncava, femenina, de color grisáceo.

CONCLUSIONES: Pequeños fragmentos de hueso humano cremado que parecen corresponder a mujer joven (20-25 años).

11/145/22. Fragmentos de bóveda craneal, humanos, quemados, de escaso espesor cortical: 2-3 mm.

Fragmento de diáfisis de cordero, grande, quemado.

Fragmento de borde de coxal de humano, adulto, quemado.

Pequeños fragmentos de huesos animales mezclados con pequeños fragmentos de huesos humanos quemados no identificables. 
11/145/27. Pequeño fragmento de falange humana quemada, de aspecto juvenil.

Raíz de molar de adulto, con ápice cerrado.

Diminutos fragmentos de hueso humano cremado, aparentemente de adulto.

$11 / 145 / 30$. Fragmentos de huesos de cordero, quemados.

CONCLUSIONES: Escasos restos óseos humanos y animales (de ovicaprino y cordero), entre los que pueden detectarse algunos de adulto (varón de 30-40 años), y otros femeninos o juveniles de edad indeterminada. Son muy escasos y pequeños los fragmentos para poder determinar biotipología. No se ha podido determinar patología ósea en ninguna de los fragmentos estudiados.

\title{
LOS RESTOS ANIMALES RECUPERADOS EN LA TUMBA 11/145 DE LA NECROPOLIS DE LOS CASTELLONES DE CEAL (JAEN)
}

\author{
POR \\ ARTURO MORALES (*) \\ FRANCISCO HERNANDEZ (*) \\ M. ${ }^{\text {a }}$ ANGELES JUARRANZ (*)
}

\begin{abstract}
RESUMEN Se describen los restos de fauna de una tumba del yacimiento de Castellones de Ceal desglosando del componente autóctono del ajuar lo que parecen ser elementos intrusivos.

ABSTRACT A description is made from faunal remains from a grave in the site of Castellones de Ceal, with special attention being paid to those elements of the assemblage which seem to be alloctonous components of the fauna.
\end{abstract}

Palabras clave Fauna, Hueso, Cáscara, Tumba, Edad del Hierro.

Key words Fauna, Bone, Eggshell, Grave, Iron Age, Spain.

\section{INTRODUCCION}

El presente trabajo constituye el segundo informe de fauna realizado en el poblado de Castellones de Ceal (Morales y Cereijo, en prensa), quedando circunscrito a la descripción de restos procedentes de una de las tumbas descubiertas en la necrópolis aneja al poblado.

(`) Laboratorio de Arqueozoología (Facultad de las Ciencias). Universidad Autónoma -E-28049 Madrid). 